This item was submitted to Loughborough's Research Repository by the author.

Items in Figshare are protected by copyright, with all rights reserved, unless otherwise indicated.

\title{
Environmental impact assessment of aviation emission reduction through the implementation of composite materials
}

\section{PLEASE CITE THE PUBLISHED VERSION}

http://dx.doi.org/10.1007/s11367-014-0824-0

\section{PUBLISHER}

(c) Springer Verlag

\section{VERSION}

AM (Accepted Manuscript)

\section{PUBLISHER STATEMENT}

This work is made available according to the conditions of the Creative Commons Attribution-NonCommercialNoDerivatives 4.0 International (CC BY-NC-ND 4.0) licence. Full details of this licence are available at: https://creativecommons.org/licenses/by-nc-nd/4.0/

\section{LICENCE}

CC BY-NC-ND 4.0

\section{REPOSITORY RECORD}

Timmis, Andrew, Alma Hodzic, Lenny Koh, Michael Bonner, Constantinos Soutis, Andreas W. Schafer, and Lynnette Dray. 2014. "Environmental Impact Assessment of Aviation Emission Reduction Through the Implementation of Composite Materials". Loughborough University. https://hdl.handle.net/2134/21192. 


\section{ENVIRONMENTAL IMPACT ASSESSMENT OF}

\section{AVIATION EMISSIONS REDUCTION}

\section{THROUGH THE IMPLEMENTATION OF}

\section{COMPOSITE MATERIALS}

Andrew J. Timmis ${ }^{l}$, Alma Hodzic ${ }^{*^{2}}$, Lenny Koh $^{l}$, Michael Bonner ${ }^{2}$, Constantinos Soutis ${ }^{3}$, Andreas W. Schäfer ${ }^{4}$, Lynnette Dray ${ }^{5}$

* Corresponding author

${ }^{1}$ Centre for Energy, Environment and Sustainability, Management School, The University of Sheffield, UK

${ }^{2}$ Composite Systems Innovation Centre, Department of Mechanical Engineering, The University of Sheffield, UK

${ }^{3}$ Aerospace Research Institute, Faculty of Engineering \& Physical Sciences, University of Manchester, UK

${ }^{4}$ UCL Energy Institute, University College London, UK

${ }^{5}$ Institute for Aviation and the Environment, The University of Cambridge, UK

Corresponding Author Details:

Professor Alma Hodzic

e-mail: a.hodzic@sheffield.ac.uk

Tel: +44 (0)1142227720 


\section{ABSTRACT}

$2 \quad$ Purpose

3 Carbon fiber reinforced polymers (CFRP) have been developed by the aviation industry to

4 reduce aircraft fuel burn and emissions of greenhouse gases. This study presents a lifecycle

5 assessment (LCA) of an all-composite airplane, based on a Boeing 787 Dreamliner. The global

6 transition of aircraft to those of composite architecture is estimated to contribute $20-25 \%$ of

7 industry $\mathrm{CO}_{2}$ reduction targets. A secondary stage of the cradle-to-grave analysis expands the

8 study from an individual aircraft to the global fleet.

9 Materials and Methods

10 An LCA was undertaken utilising Sima Pro 7.2 in combination with Ecoinvent. Eco-indicator

1199 (E) V2.05 Europe EI $99 \mathrm{E} / \mathrm{E}$ was the chosen method to calculate the environmental impact of

12 the inventory data. The previously developed Aviation Integrated Model was utilised to construct

13 a scenario analysis of the introduction of composite aircraft against a baseline projection, through

14 to 2050 , to model $\mathrm{CO}_{2}$ emissions due to their particular relevance in the aviation sector.

15 Results and Discussions

16 The analysis demonstrated CFRP structure results in a reduced single score environmental

17 impact, despite the higher environmental impact in the manufacturing phase, due to the increased

18 fossil fuel use. Of particular importance is that CFRP scenario quickly achieved a reduction in

$19 \mathrm{CO}_{2}$ and $\mathrm{NO}_{\mathrm{x}}$ atmospheric emissions over its lifetime, due to the reduced fuel consumption. The

20 modeled fleet-wide $\mathrm{CO}_{2}$ reduction of $14-15 \%$ is less than the quoted emission savings of an

21 individual aircraft $(20 \%)$ because of the limited fleet penetration by 2050 , and the increased

22 demand for air travel due to lower operating costs.

23 Conclusions 
24 The introduction of aircraft based on composite material architecture has significant

25 environmental benefits over their lifetime compared to conventional aluminum based

26 architecture, particularly with regards to $\mathrm{CO}_{2}$ and $\mathrm{NO}_{x}$ a result of reduced fuel burn. The

27 constructed scenario analyses the interactions of technology and the markets they are applied in,

28 expanding on the LCA. In this case, an observed fleet wide reduction of $\mathrm{CO}_{2}$ emission of 14-

$2915 \%$ compared to an individual aircraft of $20 \%$.

30 KEYWORDS: aviation emissions, carbon fiber reinforced polymers, composite aircraft, global

31 warming, life cycle assessment

\section{1. INTRODUCTION}

33 The combustion products of aviation fuel includes several gaseous emissions, mainly $\mathrm{CO}_{2}$,

34 nitrogen oxides $\left(\mathrm{NO}_{\mathrm{x}}\right)$, water vapor $\left(\mathrm{H}_{2} \mathrm{O}\right)$, sulphur oxides $\left(\mathrm{SO}_{\mathrm{x}}\right)$ and soot; $\mathrm{CO}_{2}, \mathrm{NO}_{\mathrm{x}}$ and $\mathrm{H}_{2} \mathrm{O}$

35 being greenhouse gases. The Intergovernmental Panel on Climate Change (IPCC, 1999) have

36 highlighted the potential impact of increased levels of greenhouse gases, both $\mathrm{CO}_{2}$ and non- $\mathrm{CO}_{2}$,

37 on the global atmospheric environment. The aviation sector currently produces around 0.71

$38 \mathrm{GtCO}_{2}(2 \%)$ of global energy related $\mathrm{CO}_{2}$ emissions (IPCC, 2014). Though this is small in

39 comparison to the transport sector (Duflou et al, 2009) as a whole $6.7 \mathrm{GtCO}_{2}(23 \%)$, aviation

40 emissions are forecast to increase through to 2050 by around $3-4 \%$ per annum due to the

41 increasing demand, approximately 5\% per annum through to 2030 (Airbus, 2011; Boeing,

42 2013a), surpassing forecast improvements in fuel efficiency of 1-1.5\% per annum (Kahn Ribeiro,

43 2007). It is appreciated by the aviation industry itself that it is unacceptable to have an

44 increasing share of global greenhouse gas emissions (IATA, 2009).

45 The aviation industry has a range of targets regarding the future control of carbon dioxide 46 emissions, the main anthropogenic greenhouse gas under consideration, through to 2050. Targets 
47 include $1.5 \%$ per annum improvement in fleet fuel efficiency, carbon neutral growth from 2020

48 and a reduction in net $\mathrm{CO}_{2}$ emissions of $50 \%$ by 2050 (ACARE, 2011; ICAO, 2013). Currently,

49 the emission of greenhouse gases from the international aviation industry is unregulated and is

50 not included in the scope of the Kyoto Protocol. Aviation is included in the European Union

51 Emission Trading Scheme (EU ETS). International aviation emissions emitted in European

52 airspace were temporarily covered by the EU Emissions Trading Scheme in 2012; at the time of

53 writing, legislation has subsequently been withdrawn to allow the development of an

54 international agreement and strategy to reduce international aviation emissions by the

55 Iinternational Civil Aviation Organization (ICAO).

56 It is widely recognised that gaseous emissions at high altitudes are more environmentally

57 damaging than those at ground level, due to increased interaction with gases in the atmosphere.

58 A parameter used to quantify the effect of aviation emission is the Radiative Forcing (RF) Index,

59 which is a measure of the impact of an agent on the energy balance of the earth's atmosphere.

60 Aircraft operation involves the emission of (a) directly radiatively active substances (e.g. $\mathrm{CO}_{2}$ or

61 water vapor); (b) chemical species that produce or destroy radiatively active substances (e.g.

$62 \mathrm{NO}_{\mathrm{x}}$, which modifies ozone concentration); and (c) substances that trigger the generation of

63 aerosol particles or lead to changes in natural clouds (e.g. contrails). These emissions and cloud

64 effects modify the chemical and particle microphysical properties of the upper atmosphere,

65 resulting in changes in RF of the earth's climate system, which can potentially lead to climate

66 change impacts and ultimately result in damage and welfare/ecosystem loss (Beck et al, 2009).

67 Emissions of particulate materials can affect both the environment, contributing to climate

68 change, and can be hazardous to human health, particularly if they are produced in the lower part

69 of the atmosphere, around airports for example. Thus, it is important to analyse the life cycle of 
70 aircraft systems and structures in as much detail as possible, in order to understand the long-term

71 impact on the human environment and the earth's ecosystem. However, on a global scale, $\mathrm{CO}_{2}$

72 and $\mathrm{NO}_{\mathrm{x}}$ emissions are greatest contributors to the global environmental impact, with the former

73 contributing thousands of times more emissions than other products of fuel burning in aviation.

74 In addition to growing concern about the environmental impact of aviation, aviation fuel is the

75 single most significant component of an airline operating cost, some $30-40 \%$ (IATA, 2009); this

76 cost is highly dependent on a volatile oil price (EC, 2008). With profit margins for the financial

77 year 2013/14 expected to be as little as 1.8\% (IATA, 2012) cost control within the airline

78 industry is highly important.

79 Carbon fiber reinforced polymer (CFRP), an advanced composite material, has been utilised as

80 a structural component in the airframes of the 'next generation' of aircraft due to its reduced

81 weight in comparison to aluminum. The Boeing 787 Dreamliner is a case in point, with $50 \%$ by

82 weight consisting of composite materials. Airframe manufacturers claim that this next

83 generation in airframe architecture can reduce fuel use, and subsequently $\mathrm{CO}_{2}$, by around 20-

84 25\% (Airbus, 2012; Boeing, 2013b).

85 This study will provide an overview of the full LCA impact analysis and focus on the emission

86 of $\mathrm{CO}_{2}$ from the combustion of jet fuel. Whilst it is widely recognised that the combustion of jet

87 fuel results in the emission of a range of pollutants, each with potentially detrimental

88 atmospheric environmental impacts, $\mathrm{CO}_{2}$ has been selected due to the importance placed on its

89 emissions by the current policy, due to its long lifetime in the atmosphere.

90 The primary purpose of this study is to present a life cycle assessment of a section of a 91 composite material aircraft, to understand the environmental impact on an individual aircraft

92 scale. This data is further used to study the impact of the introduction of an aircraft with a 
93 composite material architecture on the projected global fleet emissions through to 2050. This

94 combined simulation aims to model the effect of a transition in the global aviation fleet to the

95 next generation of aircraft architecture. $\mathrm{CO}_{2}$ and other environmental impacts are calculated

96 using socio-economic scenarios from a set of integrated energy-economy-environment models

97 against a baseline, and the results are subsequently discussed in relation to the industry targets

98 and projections of potential savings.

99 The study is here presented in two distinct parts. Methods - Stage 1 present a full life cycle

100 assessment of manufacturing, in-use and disposal stages of the composite and aluminium

101 aircrafts, including the results from this part of the study (Results - Stage 1). Methods - Stage 2

102 presents the method and outputs of the Aviation Integrated Model scenarios, including the results

103 (Results - Stage 2). Both stages of the analysis are integrated through the Discussion covering

104 numerous aspects of this complex multidisciplinary analysis and the major findings are

105 summarised in the Conclusions.

106 2. METHODS - STAGE 1

107 This paper is presented as a two-phase study; the method of enquiry of phase one is presented

108 below and subsequently the results are presented. The secondary stage of analysis is presented

109 after the LCA results.

$110 \quad$ 2.1 LCA methodology and software

111 A Life Cycle Assessment is a method of quantifying the environmental impact of a product or

112 service throughout its lifecycle from raw material extraction and processing, use phase and end 113 of life disposal (ISO, 2006). The importance of LCAs is their ability to inform where 114 environmental impacts occur and their relative importance. This enables interventions into the 115 product life-cycle that are appropriate and prevent problem-shifting of either environmental 
116 products from one to another or shifting environmental impacts from one phase of a products

117 lifecycle to another (Rebitzer, 2004).

118 A comparative LCA has been conducted on Section 46 of the Boeing 787 fuselage, due to the

119 public availability of the manufacturing data required for LCA study. The Boeing 787 airframe

120 was chosen due to the high proportion of CFRP utilised within its structure (approximately 50\%)

121 (Boeing, 2013b).

122 The LCA of fuselage section 46 of Boeing 787 was performed utilising Sima Pro 7.2 in

123 combination with the Ecoinvent database. Ecoinvent contains industrial lifecycle inventory data

124 on energy supply, resource extraction, material supply, chemicals, metals, agriculture, waste

125 management services and transport services. Eco-indicator 99 (E) V2.05 Europe EI 99 E/E was

126 the chosen method to calculate the environmental impact of the inventory data. This method

127 enables the aggregation of different impact categories into a single score value, and thus allows a

128 relative comparison between different environmental impacts to be conducted.

129 Technical data from the published literature has been utilised for the LCA where available

130 (Boeing, 2013b; Beck et al, 2009). Due to commercial sensitivity associated with the technical

131 design of the section and manufacturing processes, the research team, where appropriate, used

132 informed judgment to estimate unavailable processes data. This pragmatic simplification of the

133 LCA has been considered appropriate by the wider LCA literature (De Beaufort-Langeveld,

134 1997). Where appropriate, such assumptions are identified in this paper.

\section{$135 \quad 2.2$ LCA scenarios}

136 The LCA undertaken in this study is presented in two stages: the first stage compares the 137 equivalent sections manufactured from CFRP and Aluminum alloy through manufacturing and 
138 disposal phases, and the second phase takes into consideration of the operational emissions, and

139 hence the full life cycle,.

$140 \quad$ 2.2.1 LCA data collection and system boundaries

141 A typical weight saving of $20 \%$ (widely reported by the industry) was used as the basis for 142 comparison between the CFRP and Aluminum alloy structure (Campbell, 2004). Boeing 787

143 airframe consists of several one-piece CFRP tubesections. Section 46, being one of these tube 144 sections, was manufactured by Alenia Aeronautica, Italy. The reported mass of Section 46 is $1454000 \mathrm{lb}(1814 \mathrm{~kg}$ ) (Norris, 2009). The total reported mass is assumed to include the fuselage skin, 146 frames, stringers and floor beams. Due to the lack of specific data regarding the structure's 147 geometric properties, the section is simplified to a uniform tube shape. The effective thickness of 148 the uniform tube, calculated from the volume of the section and density of the material, is greater 149 than the fuselage skin thickness of Section 46, to account for the additional parts. The simplified 150 tube section was reported to be manufactured using a uniform automated tape laying 151 manufacturing process.

152 The length and external diameter of the section are $33 \mathrm{ft}(10.06 \mathrm{~m})$ and $19 \mathrm{ft}(5.79 \mathrm{~m})$ 153 respectively. The CFRP utilised in this study is assumed to have a density typical of the 154 material, $0.0556 \mathrm{bb} / \mathrm{in}^{3}\left(0.0277 \mathrm{~kg} / \mathrm{cm}^{3}\right)$. Applying the relationship between mass, as previously 155 reported, and density, the effective thickness of the simplified tube fuselage wall was 156 approximated at $12.95 \mathrm{~mm}$. This is a justifiable assumption, considering that the mass of the 157 section will have the influence on LCA, rather than its dimensions.

158 Prior to the manufacturing consideration, the cradle LCA scope is defined by production of 159 raw materials for each type of aircraft. CFRP consists of carbon fibres and epoxy resin. Carbon 160 fibres are produced from polyacrylonitrile (PAN) based fibers through a process called the 'PAN 
161 process', during which the fibres are carbonised at temperatures between 1800 and $2700{ }^{\circ} \mathrm{F}(980$

162 and $\left.1480{ }^{\circ} \mathrm{C}\right)$. The aerospace grade CFRP utilised in manufacturing is assumed to be composed

163 of $65 \%$ carbon fibre and $35 \%$ epoxy resin by weight, standard fractions in aerospace grade

164 CFRPs. The pre-preg tape is placed onto a cylindrical mandrel using automated tape placement

165 process and then cured in an autoclave. The layering process is repeated till the calculated

166 fuselage wall thickness is achieved. The electricity consumption, and subsequent raw material

167 consumption and emissions of electricity production, for the autoclave and pre-preg tape

168 placement, via an Automated Fibre Placement machine, has been considered. A typical Italian

169 electricity production mix has been considered.

170 The AFP robot used to manufacture Section 46 is manufactured by Ingersoll, with the energy

171 consumption estimated to be at its maximum capacity of $16,000 \mathrm{kWh}$.

172 As a comparison, the section 47 and 48 of similar dimensions are manufactured by Vought,

173 and cured in an autoclave with a power rating of $12,000 \mathrm{~kW}$ for a period of $8 \mathrm{hrs}$, hence an

174 estimated total energy consumption was 96,000 kWh.

175 The disposal of the composite section is assumed to be landfill. This assumption is discussed 176 in greater details in the LCA results section. The parameters used in LCA of manufacturing of 177 the composite section were intentionally chosen at the extreme end, in order to avoid any 178 potential bias towards the utilisation of composite materials compared to their metallic 179 counterparts. It was expected that the operational stage LCA would be overwhelmingly 180 favourable towards utilisation of composites, due to the significant fuel savings and 181 proportionally lower life cycle emissions.

$182 \quad$ 2.2.2 LCA of aluminum alloy structure manufacturing 
183 Two scenarios have been presented for the conventional aerospace aluminum alloy analysis 184 and comparison. The buy-to-fly (BTF) ratio is the amount of metal utilised to manufacture a part, 185 and this can be as high as 25:1 for aerospace components. For an average commercial aircraft

186 the buy-to-fly ratio is estimated to be 8:1. Hence, two scenarios are presented below: Al

187 Scenario 1, an idealised scenario with a buy-to-fly ratio of 1:1 and Al Scenario 2 with a more

188 realistic and still $\mathrm{Al}$ favourable buy-to-fly ratio of 8:1. The two scenarios will be referred to as $\mathrm{Al}$

189 Scenario 1 and Al Scenario 2 respectively, and will be used here as the variables representative 190 of the idealised and the standard manufacturing practice.

191 The mass of $\mathrm{Al}$ alloy utilised in the fuselage is estimated to be $25 \%$ more (Campbell, 2006)

192 than the CFRP section, 2267kg. The aluminum ingots are hot rolled and subsequently machined

193 into the final part. Recycling of aluminum is highly efficient requiring between 6-7\% of the 194 energy required for primary production (IEA, 2009). In current practice, recycled aluminum is 195 not utilised in the production of aircraft parts. In SimaPro LCA software database, recycled 196 aluminum is credited with positive emissions. The disposal scenarios for this analysis are 197 assumed to be $100 \%$ recycling for aluminium in order to approach the generic lightweight 198 advantage of CFRP with the most onerous comparison for CFRP case.

$199 \quad$ 2.2.3 Additional consideration of in-use phase

200 As previously stated, LCA covers all phases of a product lifecycle from manufacture, use and 201 final disposal. The following in-use analysis of Boeing 787 makes a number of initial 202 assumptions; one, the aircraft has a range of 14,000km (Boeing, 2013b) and a life-span similar to 203 a typical commercial aircraft of 30-years (Peel, 1995); two, the aircraft is assumed to operate 204 daily, leading to the distance travelled by an aircraft during its lifetime of 150 million $\mathrm{km}$. 
205 For this stage of the analysis it is important to define the functional unit. The unit for 206 comparison is tonne-km (tkm); the mass of the comparable unit multiplied by the distance 207 travelled.

\section{3. RESULTS - STAGE 1}

\section{$209 \quad 3.1$ LCA results - manufacture and disposal}

210 Figure 1 shows the single score environmental impact for the three manufacturing and disposal 211 scenarios considered in this study. The CFRP manufacturing scenario is demonstrated to have

212 higher emissions than both Al Scenario 1 and Al Scenario 2, as expected, due to the higher 213 energy power consumed during the carbon fiber production. The most significant contributor to 214 the increased environmental burden is due to fossil fuel use, a parameter more evident in the 215 normalisation plot of the environmental impact categories in Figure 2. The standard Eco216 indicator values are dimensionless, similar to units of currency. In the Eco-99 system, the unit of 217 measurement is called the Eco-indicator Point, Pt. The size of the Pt unit was chosen by Eco-99 218 to represent one thousandth of the annual environmental load of an average citizen in Europe.

219 The primary environmental impacts of concern within the aviation industry are the gaseous 220 emissions of $\mathrm{CO}_{2}$ and $\mathrm{NO}_{x}$ (ACARE, 2002; IATA, 2009), however other contributing factors are

221 also analysed for a more complete understanding of the full environmental impact. Figure 3 222 quantifies the emissions of both gases through the manufacturing and disposal phase for the three 223 material scenarios. The same trend as seen in the single score environmental impact is present 224 here, with CFRP manufacturing being more environmentally burdensome, with respect to both $225 \mathrm{CO}_{2}$ and $\mathrm{NO}_{\mathrm{x}}$.

$226 \quad 3.2$ LCA results - consideration of in-use phase 
227 Figure 4 shows the single score environmental impact for the three full LCA scenarios

228 considered in this study. The assessment demonstrates that the CFRP section results in a

229 decreasing environmental impact when compared to both scenarios in Al alloy section analysis.

230 Additionally, the environmental burden in the three scenarios is dominated by the consumption

231 of jet-fuel in the in use phase, and in turn the environmental impact resulting from manufacturing

232 and disposal can be considered negligible or insignificant in all the scenarios, as shown in our 233 earlier study (Scelsi et al, 2011).

234 As previously, the emissions of $\mathrm{NO}_{\mathrm{x}}$ and $\mathrm{CO}_{2}$ are presented separately (Figure 5). The CFRP 235 section results in a significant decrease in the emissions of both gaseous substances, $19 \%$ and $23620 \%$ respectively.

\section{$237 \quad$ 3.2.1 LCA break-even distance/time}

238 An additional stage of analysis undertaken by this study determined the distance and the hours 239 of operation of an aircraft at which the CFRP section becomes environmentally beneficial. As 240 demonstrated in the previous section, it is in the 'in-use' phase that the CFRP reverses the 241 environmental deficit of production and disposal stage; the amount of hours of operation can be 242 estimated. By negating the ascent and descent stages of the aircraft flight-path and assuming that 243 the aircraft operates at a cruise speed of $950 \mathrm{~km} / \mathrm{h}$ (Boeing, 2013b) the operation time can be 244 determined. The cumulative single score impact of three modeled scenarios calculated the break 245 even distances for CFRP against Al1 and Al2 as 190,000km (210 hrs in operation) and 75,000km 246 (83 hrs) respectively. Likewise, break-even distances for both $\mathrm{CO}_{2}$ and $\mathrm{NO}_{\mathrm{x}}$ were calculated 247 (Table 1).

248 The results imply that the break-even point in the emissions consumption and savings is 249 achieved after only a few international flights, and the manufacturing emissions can be hence 
250 neglected in the analysis of the global impact of aviation in the atmospheric emissions. The fuel

251 consumption savings play a far more important part in achieving the emissions savings in the

252 future air transport.

253 4. METHODS - STAGE 2

$254 \quad$ 4.1 The AIM aviation systems model

255 As previously highlighted, the introduction of composite material aircraft has been identified 256 as a method of achieving long-range industry targets for carbon emission reduction (IATA, 257 2009). The motivation in the aviation industry to introduce composite material aircraft is for both 258 environmental and economic factors (Mason, 2007). The second stage of this study considers the 259 impacts of a transition of the global aviation fleet to composite aircraft models with the aim of 260 understanding how the aircraft variants are adopted in the global market and how the resulting 261 carbon emissions reductions compare to those estimated per-aircraft as above (Helms \& 262 Lambrecht , 2007; Givoni \& Rietveld , 2009).

263 This study utilises a previously developed model, the Aviation Integrated Modelling (AIM) 264 (Reynolds, 2007), to simulate global aviation system responses to changes in costs and available 265 technologies. AIM consists of seven interconnected modules modeling demand for air travel, 266 routing and scheduling, airline costs and technology adoption, flight routing and emissions, local 267 and global emissions impacts and regional economics, run iteratively until equilibrium between 268 demand and supply is reached. For this study we concentrate on $\mathrm{CO}_{2}$ and neglect the local 269 emissions and regional economics modules.

270 AIM requires internally consistent scenarios of future population, gross domestic product 271 (GDP) and oil prices to project demand and technology adoption. For these scenarios we use the 272 outputs of three integrated assessment models used for a U.S. climate change mitigation study 
273 (Clarke et al, 2007): IGSM (Integrated Global System Model), MERGE (Model for Evaluating

274 the Regional and Global Effects) and MiniCAM (Mini-Climate Assessment Model), shown in

275 Table 2. Two technology scenarios were constructed: a baseline analysis, in which current

276 airframe technology continues to be used, and a second scenario where aircraft models utilising

277 composite materials technology are introduced.

278 The commercial aviation fleet is assumed to consist of three representative aircraft variants.

279 The defined aircraft variants have been determined by size with aircraft representing small

280 (narrow-body, short to medium range), medium (wide-body, medium to long range) and large 281 (wide-body, medium to long range) aircraft. The three aircraft variants are deemed to be

282 representative of the overwhelming majority of commercial aircraft classes as represented in 283 industry literature (Airbus, 2011; Boeing, 2013a). Table 3 summarises the physical 284 characteristics and relative performance of the reference conventional and composite aircraft 285 variants.

286 The composite material aircraft proposed for all size classes are assumed to be a suitable 287 substitute for $100 \%$ of the aircraft fleet of that category. The size class defined as large includes 288 those aircraft deemed very large, e.g. Airbus A380. The proportion of aircraft in the very large 289 class is only 5\% of new passenger aircraft delivered in the period 2011-2030 (Airbus, 2011) and 290 is therefore not defined separately.

291 To better isolate the impact of composite materials, the modeling only considers the effect of a 292 transition in airframe technology and associated evolutionary improvements in engine 293 technology, from those used in the reference aircraft to composite material variants. The model 294 does not take into account any technology transition in aircraft engine technology (e.g. open295 rotor engines), the use of biofuels, operational changes relating to air transport movements 
296 (ATMs) or the introduction of emission trading. In addition, we do not consider the next

297 generation of aircraft after those modeled. For these reasons, total emissions are likely to err on

298 the high side of those achievable.

299 5. RESULTS - STAGE 2

$300 \quad 5.1$ AIM results

301 As discussed above, two technology scenarios are modeled for each of the three socio302 economic scenarios:

303 I. Reference simulation - continuation of conventional technology, and

304 II. Availability of composite material aircraft.

305 The primary driver for the adoption of composite material aircraft is the oil price, which 306 influences whether fuel-saving technologies will be cost-effective (Table 2). 

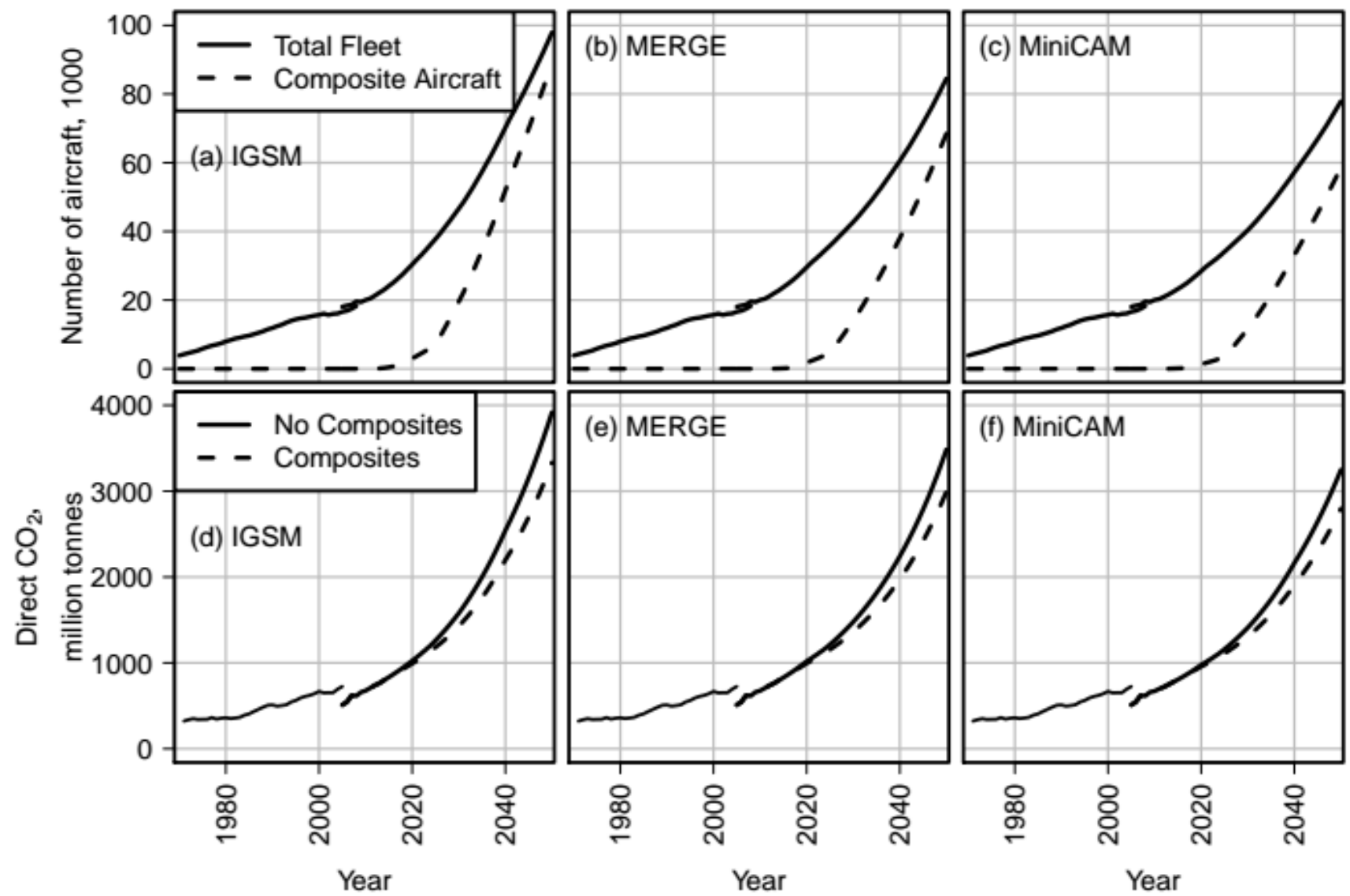

307

308 Figure 6 (a, b and c [top row]) shows the total number of aircraft in the global fleet and the

(e) MERGE

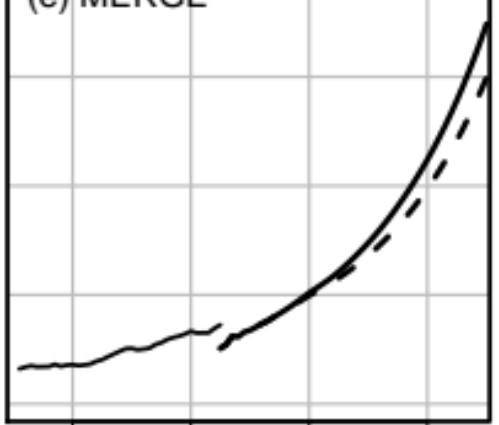

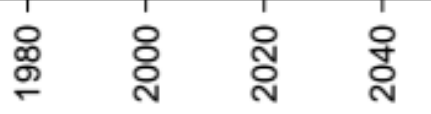

유

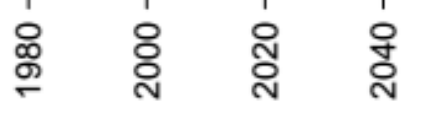

Year

309 proportion of composite aircraft. The total size of the fleet by 2050 is predicted to be between

31095,000 and 77, 500 aircrafts. In all three socio-economic scenarios by 2050 composite material

311 aircraft compose the majority of the aviation fleet but did not achieve $100 \%$ penetration. Fleet

312 penetration is dependent upon rates of fleet growth with time, which depend in turn on GDP and

313 population projections, and the relative oil price modeled in each scenario. The high uptake of

314 composite material aircraft in all scenarios indicates that they are cost-effective to operate in all

315 cases modeled.

316 Figure 6 (d, e and $\mathrm{f}$ [bottom row]) shows the modeled $\mathrm{CO}_{2}$ emissions of the global aviation

317 fleet through to 2050 for each of three socio-economic scenarios utilised in this study. Historic

318 global aviations emissions (pre-2005) collected by the International Energy Agency (IEA, 2007a; 
319 IEA, 2007b) are plotted in addition to the simulation. $\mathrm{CO}_{2}$ emissions are predicted to be reduced

320 by between $14-15 \%$ by 2050 due to the introduction of composite aircraft, relative to the baseline

321 scenario. It should be noted that the observed discrepancy between the AIM and IEA values is

322 due to the fact that the IEA figures include all aviation, whereas AIM models $95 \%$ of scheduled

323 passenger revenue passenger kilometres RPKs. AIM does not account for freight and

324 unscheduled flights (Reynolds, 2007). Table 4 presents the numerical values for each scenario

325 output in this analysis, showing absolute values for the aviation fleets with and without the 326 implementation of composites.

\section{6. DISCUSSION}

\section{$328 \quad 6.1 \mathrm{LCA}$}

329 The results of the LCA clearly highlight that the environmental impact of an aircraft is 330 dominated by the in-use phase. The reader should note the difference in scale between the single 331 score environmental impact of Fig. 1 (manufacturing and disposal phases) and Fig. 4 (inclusive 332 of in-use phase) being measured in $\mathrm{kPt}$ and MPt respectively. Despite an increased 333 environmental burden through the utilisation of CFRP at the manufacturing and disposal stage, 334 particularly as a result of fossil fuel use, this is negligible when taken into consideration with the 335 in-use phase.

336 The LCA scenarios presented for conventional aluminum airframe architecture (AL1 and AL2), 337 present onerous comparison for the CFRP. The assumption of a 100\% recycled waste disposal 338 route reduced the single score environmental impact of both scenarios, due to this being deemed 339 a positive impact in SimaPro LCA software. The disposal route for CFRP is assumed to be 
340 landfill, due to the lack of current recycling routes for a relatively new and novel material

341 (Pickering, 2006; Witik, 2013)

\section{$342 \quad 6.2$ Global Aviation}

343 The benefits of a transition of the global passenger aviation fleet to composite material aircraft

344 goes beyond the direct $14-15 \% \mathrm{CO}_{2}$ savings predicted in this study. The benefit of composite

345 material aircraft implementation also includes globally reduced fuel consumption and therefore

346 potentially lower direct operating costs, due to an improved lift-to-drag ratio and reduced weight.

347 The reduction in fuel consumption leads to reduced $\mathrm{CO}_{2}$ emissions and in addition reduced 348 emissions in all combustion products (including $\mathrm{NO}_{\mathrm{x}}$ and water vapour). The reduction in 349 engine combustion products is more beneficial than a targeted intervention solely aimed at a net 350 reduction in $\mathrm{CO}_{2}$ emissions, for example the introduction of biomass derived jet fuel.

351 The industry target of $\mathrm{CO}_{2}$ reduction by $50 \%$ on a RPK basis by 2020 cannot be achieved solely 352 by the introduction of airframes utilising a high proportion of composite material, as 353 demonstrated in this study. Though this novel lightweight technology is an important component 354 in reducing the environmental impact of aviation, it is a step change in technology that must be 355 considered in conjunction with a range of other technological and operational improvements.

356 The Advisory Council for Aviation Research and Innovation in Europe (ACARE,2002) goal of 357 reducing fuel consumption per RPK by 50\% for new aircraft entering service after 2020 is split 358 between technological improvements in engine and airframe technology, 15-20\% and $20-25 \%$ 359 respectively. The remainder of $50 \%$ reduction is to be achieved through improvements in 360 operational procedures air transport movements (ATM). Long-term ACARE goals through to 3612050 include $75 \%$ reduction in $\mathrm{CO}_{2}$ emissions per passenger kilometer relative to 2000 
362 (ACARE, 2002). The composite aircraft utilised in this study achieves the primary goal for a 363 reduction in fuel consumption for aircraft entering the fleet post-2020. To achieve the long364 range goals of a $75 \%$ reduction would require a step change in aircraft design towards a blended 365 wing body aircraft, which presents significant technical challenges, and technology readiness is 366 predicted around 2037-38 (Vera Morales, 2011).

367 Greenhouse gas emissions from international aviation have not been included in the previous 368 international programmes to tackle global warming and anthropogenic climate change. The 369 inclusion of international aviation in the European Union Emissions Trading Scheme (EU ETS) 370 in 2012 has since been suspended pending the formation of an international agreement at the 3712014 ICAO annual general meeting. Calls from within the aviation industry are for single 372 market based mechanism (MBM) that “... should contribute towards achieving global 373 aspirational goals" (ICAO, 2011). Presently no MBM has been developed.

374 The lifetime of an aircraft airframe can be up to 30-years (Kahn Ribeiro, 2007) and those aircraft 375 models entering service before 2020 could very well still be in operation by 2050 , the end of the 376 modeling period used in this study. The predicted growth in aviation demand to 2030 alone will 377 require the delivery of between 27, 000 and 33, 500 new passenger aircraft (Airbus, 2011; 378 Boeing 2013) equating to an order value of approximately $\$ 4$ trillion. As was highlighted in this 379 study the emission reduction potential of composite aircraft was limited due to fleet penetration 380 not being $100 \%$ by 2050 .

381 Despite an increased environmental impact of CFRP during manufacture and disposal, the 382 section under analysis demonstrates a significant reduction in impact over its lifetime. The 
383 reduced impact is due to the in-use phase and consumption of jet-fuel that far outweighs the

384 impact of manufacture and disposal.

385 Under all three socio-economic scenarios utilised in this study, the potential reduction in 386 emissions of carbon dioxide due to a transition of the aircraft fleet to composite materials was

387 14-15\% compared to a baseline projection using current technology in 2050 - a reduction in 388 cumulative $2010-2050$ emissions of $9-11 \%$. Reductions in the emission of carbon dioxide is less

389 than the quoted technical potential of $20-25 \%$ due to fleet penetration not being total and a 390 passenger and service demand increase of 6-9\% by 2050; the result of reduced operating costs of 391 composite material aircraft resulting in lower ticket prices.

\section{7. CONCLUSIONS}

393 The life cycle assessment demonstrates a reduction in the environmental impacts through the 394 transition of airframe architecture from conventional aluminum to CFRP. It was shown that 395 CFRP was preferable even in the most favorable aluminum scenario (low buy-to-fly ratio and 396 waste $100 \%$ recycled). Furthermore, the study highlighted how the life cycle environmental 397 impact of aircraft is dominated by the in-use phase, particularly the consumption of fossil fuels 398 and the release of $\mathrm{CO}_{2}$ and $\mathrm{NO}_{\mathrm{x}}$ related to the combustion of aviation fuel.

399 The conventional LCA presented in this study supported industry claims of a reduction in carbon 400 emissions through the introduction of composite material airframe architecture. However, the 401 secondary analysis, utilising the AIM model, demonstrates the potential reduction in carbon 402 emissions were less than predicted due to an interaction of technology and market, in this case a 403 positive rebound in demand due to lower ticket prices. 
404 The conclusions of this study highlight the importance of creating a market based mechanism for

405 carbon dioxide that supports the market adoption of more fuel efficient aircraft but also addresses

406 potential uplift in demand as a result of the reduced operational costs of composite material

407 aircraft. The results of this study were based on a simplified CFRP tube section, due to the lack

408 of technical process data in the public arena. It is recommended that additional study should be

409 undertaken with more detailed manufacturing process data and structural airframe components,

410 both of CFRP and aluminum. An extension to this study would be to conduct a hybrid LCA to

411 estimate indirect and direct emissions from the wider supply chain.

\section{8. ACKNOWLEDGMENT}

413 This study has been carried out independently using the information available in the public

414 domain. The authors wish to thank Bart Moenster, John Baumann and David Heck from Boeing

415 for their motivational support.

\section{9. REFERENCES}

417 Advisory Council for Aeronautics Research in Europe (2002) Strategic research agenda.

418 Luxembourg: Publications Office of the European Union

$419 \mathrm{http} / /$ www.acare4europe.org/sites/acare4europe.org/files/document/ASD-volume1-2nd-

$420 \quad$ final-ss\%20illus-171104-out-asd.pdf

421 Advisory Council for Aeronautics Research in Europe (2011) Flightpath 2050: Europe's vision

422 for aviation. Luxembourg: Publications Office of the European Union.

423 http://ec.europa.eu/transport/modes/air/doc/flightpath2050.pdf

424 Airbus (2012) Facts \& figures: A350 XWB eco-efficiency. Toulouse: Airbus.

425 http://www.airbus.com/presscentre/presskits/?eID=dam_frontend_push\&docID=27412 
426

Airbus (2011) Global market forecast 2011-2030. Toulouse: Airbus Group. http://www.airbus.com/company/market/forecast/?eID=dam_frontend_push\&docID=337 55

Beck A J, Hodzic A, Soutis C, Wilson C W (2009) Influence of implementation of composite materials in civil aircraft industry on reduction of environmental pollution and greenhouse effect, IOP Conf. Ser.: Mater. Sci. Eng. 26012015

Boeing (2013a) Current market outlook. Chicago: Boeing. http://www.boeing.com/assets/pdf/commercial/cmo/pdf/Boeing_Current_Market_Outloo k_2013.pdf

Boeing (2013b) 787 Dreamliner: program fact sheet. Chicago: Boeing. http://www.boeing.com/boeing/commercial/787family/programfacts.page

Campbell F C (2004) Manufacturing processes for advanced composites. Amsterdam: Elsevier

Campbell F C (2006) Manufacturing technology for aerospace structural material. Oxford: Elsevier

Clarke L E, Edmonds J A, Jacoby H D, Pitcher H M, Reilly J M, Richels R G (2007) Scenarios of greenhouse gas emissions and atmospheric concentrations. Sub-report 2.1A of Synthesis and Assessment Product 2.1 by the US Climate Change Science Program and the Subcommittee on Global Change Research. Washington DC: Department of Energy, Office of Biological and Environmental Research

De Beaufrt-Langeveld A, van den Berg N, Christiansen K, Haydock R, ten Houten M, Kotaji S (1997) Simplifying LCA: just a cut? Final report of the SETAC Europe Screening and Streamlining Working Group. Amsterdam: SETAC

Duflou J R, De Moor J, Verpoest I, Dewulf W (2009). Environmental impact analysis of composite use in car manufacturing. CIRP Annals - Manufacturing Technology, vol. 58, issue 1, pp. 9-12.

European Commission (2008) Fuel and air transport. Brussels: European Commission. http://ec.europa.eu/transport/modes/air/doc/fuel_report_final.pdf 
Givoni M, Rietveld P (2009) The environmental implications of airlines' choice of aircraft size. Journal of Air Transport Management, vol. 16, issue 3, pp. 159-167.

Helms H, Lambrecht U (2007) The Potential Contribution of Light-weighting to Reduce Transport Energy Consumption. International Journal of Life Cycle Assessment, pp. 5864.

Intergovernmental Panel on Climate Change (1999) Aviation and the global atmosphere: a special report of IPCC Working Groups I and III in collaboration with the Scientific Assessment Panel to the Montreal Protocol on Substances that Deplete the Ozone Layer; Penner, E. P., Lister, D. H., Griggs, D. J., Dokken, D. J., McFarland, M., Eds.; Cambridge University Press: Cambridge, U.K., 1999

International Air Transport Association (2009) The IATA technology roadmap report. Montreal: International Air Transport Association. http://www.iata.org/whatwedo/environment/Documents/technology-roadmap-2013.pdf

International Air Transport Association (2012) Financial forecast June 2012. Montreal: International Air Transport Association. https://www.iata.org/whatwedo/Documents/economics/Industry-Outlook-Jun2012.pdf

International Civil Aviation Organisation (2013) Report of the executive committee on agenda item 17 (section on climate change). Montreal: International Civil Aviation Organization. http://www.icao.int/Meetings/a38/Documents/WP/wp430_en.pdf

International Civil Aviation Organisation (2011) The thirty-fifth session of the UNFCCC Subsidiary Body for Scientific and Technological Advice, agenda item 9(a). Montreal: International Civil Aviation Organization. http://www.iata.org/pressroom/Documents/annual-report-2011.pdf

International Energy Agency (2007a) Energy statistics of OECD countries 2007. Paris: OECD/IEA.

International Energy Agency (2007b) Energy statistics of non-OECD countries 2007. Paris: OECD/IEA. 
International Energy Agency (2009) Energy technology transitions for industry. Paris: OECD/IEA

International Standardization Organization (2006) ISO14040 International Standard. In:

Environmental management - lifecycle assessment - principles and framework. Geneva: International Organisation for Standardization

Kahn Ribeiro, S, Kobayashi, S et al. (2007) Transport and its infrastructure. In: Metz, B, Davidson, O R, Bosch, P R, Dave, R, Meyer, L A (eds) Climate change 2007: mitigation of climate change Contribution of Working Group III to the Fourth Assessment Report of the Intergovernmental Panel on Climate Change. Cambridge University Press: Cambridge and New YorkMason K J (2007) Airframe manufacturers: which has the better view of the future? J Air Transp Manag 13(1): 9-15

Norris G, Wagner M (2009) Boeing 787 Dreamliner; Minneapolis: Zenith Press

Peel C J, Gregson P J (1995) Design requirements for aerospace structural materials. In: Flower H M (ed) High performance materials in aerospace; London: Chapman \& Hall: London, pp 1-48

Pickering S J (2006) Recycling technologies for thermoset composite materials: current status. Composites Part A 37(8): 1206-1215

Rebitzer G, Ekvall T, Frischknecht R, Hunkeler D, Norris G, Rydberg T, Schmidt W, Suh S, Weidema B P, Pennington D W (2004) Life cycle assessment Part 1: Framework, goal and scope definition, inventory analysis and application. Environ Int 30(5):701-720

Reynolds T, Barrett S, Dray L, Evans A, Kohler M, Vera-Morales M et al. (2007) Modelling environmental \& economic impacts of aviation: introducing the aviation integrated modelling project. Presented at the $7^{\text {th }}$ AIAA Aviation Technology, Intergration and Operations Conference. Belfast

Scelsi L, Bonner M, Hodzic A, Soutis C, Wilson C, Scaife R, Ridgway K (2011) Potential emissions savings of lightweight composite aircraft components evaluated through life cycle assessment, Express Polymer Letters 5(3):209-217 2011. 
Sims R, Schaeffer R, Creutzig F, Cruz-Núñez X, D’Agosto M, Dimitriu D, Figueroa Meza M J,

Vera-Morales M, Graham W, Hall C, Schäfer A (2011) Techno-economic analysis of aircraft. Sperling D, Tiwari G (2014) Transport. In: Climate Change 2014: Mitigation of Climate Change. Contribution of Working Group III to the Fifth Assessment Report of the Intergovernmental Panel on Climate Change. Edenhofer, O., R. Pichs-Madruga, Y. Sokona, E. Farahani, S. Kadner, K. Seyboth, A. Adler, I. Baum, S. Brunner, P.

Eickemeier, B. Kriemann, J. Savolainen, S. Schlömer, C. von Stechow, T. Zwickel and J.C. Minx, Eds.; Cambridge University Press, Cambridge, United Kingdom and New York, NY, USA

Cambridge: University of Cambridge.

http://www.toscaproject.org/FinalReports/TOSCA_WP2_Aircraft.pdf

Witik R A, Teuscher R, Michaud V, Ludwig C, Månson J E (2013) Carbon fibre reinforced composite waste: an environmetnal assessment of recycling, energy recovery and landfilling. Composites Part A 49(1):89-99

\section{TABLES}

Table 1. Break-even distances and time (hours of flying) for CFRP vs. Al1 and Al2.

\begin{tabular}{|l|l|l|l|l|}
\hline \multirow{2}{*}{} & \multicolumn{2}{|l|}{ CFRP vs. AL1 } & CFRP vs. AL2 \\
\cline { 2 - 5 } & Distance $(\mathrm{km})$ & Time $(\mathrm{h})$ & Distance $(\mathrm{km})$ & Time $(\mathrm{h})$ \\
\hline Carbon dioxide & 170000 & 188 & 95000 & 105 \\
\hline Nitrogen oxides & 90000 & 99 & 70000 & 77 \\
\hline
\end{tabular}

527 Table 2. Socio-economic model inputs into the Aviation Integrated Model (AIM).

\begin{tabular}{|l|l|l|l|l|l|l|l|l|}
\hline Input & Scenario & USA & Western & $\begin{array}{l}\text { Eastern } \\
\text { Europe/Former }\end{array}$ & China & India & Japan & $\begin{array}{l}\text { Africa/Latin } \\
\text { America/Rest }\end{array}$ \\
\hline
\end{tabular}




\begin{tabular}{|c|c|c|c|c|c|c|c|c|}
\hline Parameter & & & Europe $^{\mathrm{a}}$ & Soviet Union & & & & of the world \\
\hline \multirow{3}{*}{$\begin{array}{l}\text { Population } \\
\text { growth rate } \\
\% / \text { year }^{\mathrm{b}}\end{array}$} & IGSM & 0.6 & -0.2 & -0.3 & 0.3 & 0.9 & -0.2 & 1.3 \\
\hline & MERGE & 0.4 & 0.0 & -0.1 & 0.3 & 0.7 & 0.0 & 1.1 \\
\hline & MiniCAM & 0.6 & 0.0 & -0.1 & 0.2 & 0.8 & -0.2 & 1.2 \\
\hline \multirow{3}{*}{$\begin{array}{l}\text { GDP/capita } \\
\text { growth rate, } \\
\% / \text { year }^{b}\end{array}$} & IGSM & 2.2 & 2.9 & 4.0 & 4.0 & 2.5 & 3.1 & 1.9 \\
\hline & MERGE & 1.4 & 1.7 & 3.4 & 4.5 & 4.3 & 1.3 & 2.5 \\
\hline & MiniCAM & 1.3 & 1.0 & 3.3 & 5.1 & 4.8 & 1.2 & 1.9 \\
\hline \multirow{3}{*}{$\begin{array}{lr}\text { Oil price, } \\
\$ 2005 \text { per } \\
\text { bbl }\end{array}$} & IGSM & \multicolumn{7}{|c|}{$106(2020), 154(2040)$} \\
\hline & MERGE & \multicolumn{7}{|c|}{$82(2020), 124(2040)$} \\
\hline & MiniCAM & \multicolumn{7}{|c|}{$74(2020), 92(2040)$} \\
\hline
\end{tabular}

${ }^{\mathrm{a}}$ The country composition of geographic regions in each socio-economic are different and as such a direct comparison of values is limited. Full country lists are presented in (Clarke et al, 530 2007)

$531 \quad{ }^{\mathrm{b}}$ Mean values for 2005-2050 (Clarke, 2007)

533 Table 3. Substitute aircraft utilised and their operational performance.

\begin{tabular}{|l|l|l|l|}
\hline Size Class & Large & Medium & Small \\
\hline Definition (No. Seats) & $>299$ & $190-299$ & $100-190$ \\
\hline Reference Aircraft & Boeing 777-300 & Airbus A330-300 & Airbus A319-131 \\
\hline Reference Engine & Rolls Royce Trent 895 & $\begin{array}{l}\text { General Electric CF6 } \\
80 \mathrm{E} 1 \text { A2 }\end{array}$ & V2511 \\
\hline Composite Aircraft & A350-1000 & Boeing 787 & $\begin{array}{l}\text { TOSCA composite } \\
\text { aircraft }\end{array}$ \\
\hline Year of Fleet Entry & 2017 & $2012^{\mathrm{a}}$ & $2025^{\mathrm{b}}$ \\
\hline $\begin{array}{l}\text { Purchase Price (\$m) } \\
\text { Maintenance Cost }\end{array}$ & $205.8^{\mathrm{b}}$ & $148.7^{\mathrm{c}}$ & $67.0^{\mathrm{b}}$ \\
\hline $\begin{array}{l}\text { Fuel Use (against } \\
\text { reference aircraft) }\end{array}$ & $25 \%$ lower $^{\mathrm{e}}$ & $20 \%$ lower $^{\mathrm{f}}$ & $22 \%$ lower $^{\mathrm{b}}$ \\
\hline
\end{tabular}


${ }^{a}$ Closest full year of operation. First fleet entry late-2011.

${ }^{\mathrm{b}}$ TOSCA mid-range estimate (Vera Morales, 2011)

${ }^{c}$ Average of Boeing 787 subtypes. Assumed 20\% discount from list price

d TOSCA estimate. Boeing 787 factsheet relative to 'comparable aircraft types' (Boeing, 2013b)

$540 \quad$ e Airbus 350 factsheet relative to 'current competitor' (Airbus, 2012)

$541 \quad{ }^{\mathrm{f}}$ Boeing 787 factsheet relative to 'comparable aircraft types' (Boeing, 2013b)

543 Table 4. A summary of the outputs for each scenario in AIM analysis.

\begin{tabular}{|c|c|c|c|c|c|c|}
\hline \multirow{2}{*}{$\begin{array}{l}\text { Output } \\
\text { Parameter }\end{array}$} & \multirow[t]{2}{*}{ Scenario } & \multirow{2}{*}{$\begin{array}{l}2005 \\
\text { value }\end{array}$} & \multicolumn{2}{|l|}{2020 value } & \multicolumn{2}{|l|}{2050 value } \\
\hline & & & $\begin{array}{l}\text { No } \\
\text { Composites }\end{array}$ & Composites & $\begin{array}{l}\text { No } \\
\text { Composites }\end{array}$ & Composites \\
\hline \multirow{3}{*}{$\begin{array}{l}\text { Direct } \\
\mathrm{CO}_{2}, \mathrm{Mt}\end{array}$} & IGSM & \multirow{3}{*}{$510^{\mathrm{a}}$} & 1025 & 993 & 3917 & 3333 \\
\hline & MERGE & & 1019 & 996 & 3485 & 2994 \\
\hline & MiniCAM & & 976 & 957 & 3247 & 2796 \\
\hline \multirow{3}{*}{$\begin{array}{l}\text { Direct } \\
\mathrm{CO}_{2}, \quad \mathrm{Mt} \\
\text { per pkm }\end{array}$} & IGSM & \multirow{3}{*}{0.135} & 0.125 & 0.118 & $0.127^{\mathrm{c}}$ & 0.100 \\
\hline & MERGE & & 0.125 & 0.120 & 0.127 & 0.103 \\
\hline & MiniCAM & & 0.125 & 0.121 & 0.127 & 0.105 \\
\hline \multirow{3}{*}{$\begin{array}{l}\text { Global } \\
\text { fleet, } \\
\text { number }\end{array}$} & IGSM & \multirow{3}{*}{18100} & 29900 & 30400 & 92000 & 97900 \\
\hline & MERGE & & 29400 & 29600 & 80300 & 84500 \\
\hline & MiniCAM & & 28200 & 28400 & 74600 & 77800 \\
\hline
\end{tabular}

544

545

546

547

548

549

${ }^{a}$ IEA (2007) give global direct aviation $\mathrm{CO}_{2}$ in 2005 as $725 \mathrm{Mt}$; this includes freight and unscheduled flights which are not modelled in AIM.

${ }^{\mathrm{b}}$ Since freight is not directly modelled in AIM, we use passenger kilometers (pkm) as a basis for comparison rather than tonne-kilometres (tkm) here.

${ }^{c}$ The rise in $\mathrm{CO}_{2}$ per pkm reflects changing use patterns of aircraft; for a given individual flight emissions in this scenario are similar to those in 2020. 


\section{FIGURE CAPTIONS}

552 Figure 1 Single score environmental impact comparison of the three scenarios: Al1 (BTF ratio

553 1:1), A12 (BTF ratio 8:1) and CFRP section in manufacturing and disposal phase.

554 Figure 2 Normalization plot of environmental impact for the three scenarios by impact category.

555 Figure 3 Quantities of $\mathrm{CO}_{2}$ and $\mathrm{NO}_{\mathrm{x}}$ produced in manufacturing and disposal of composite 556 airframe section.

557 Figure 4. A complete LCA single score environmental impact comparison of the three scenarios 558 used in this study.

559 Figure 5. Quantities of $\mathrm{CO}_{2}$ and NOx produced from the complete LCA of the three scenarios 560 used in this study.

561 Figure 6 Modeled fleet penetrations of composite aircraft (top). Modeled emission of $\mathrm{CO}_{2}$ 562 through to 2050 (bottom).

563 10. FIGURES 


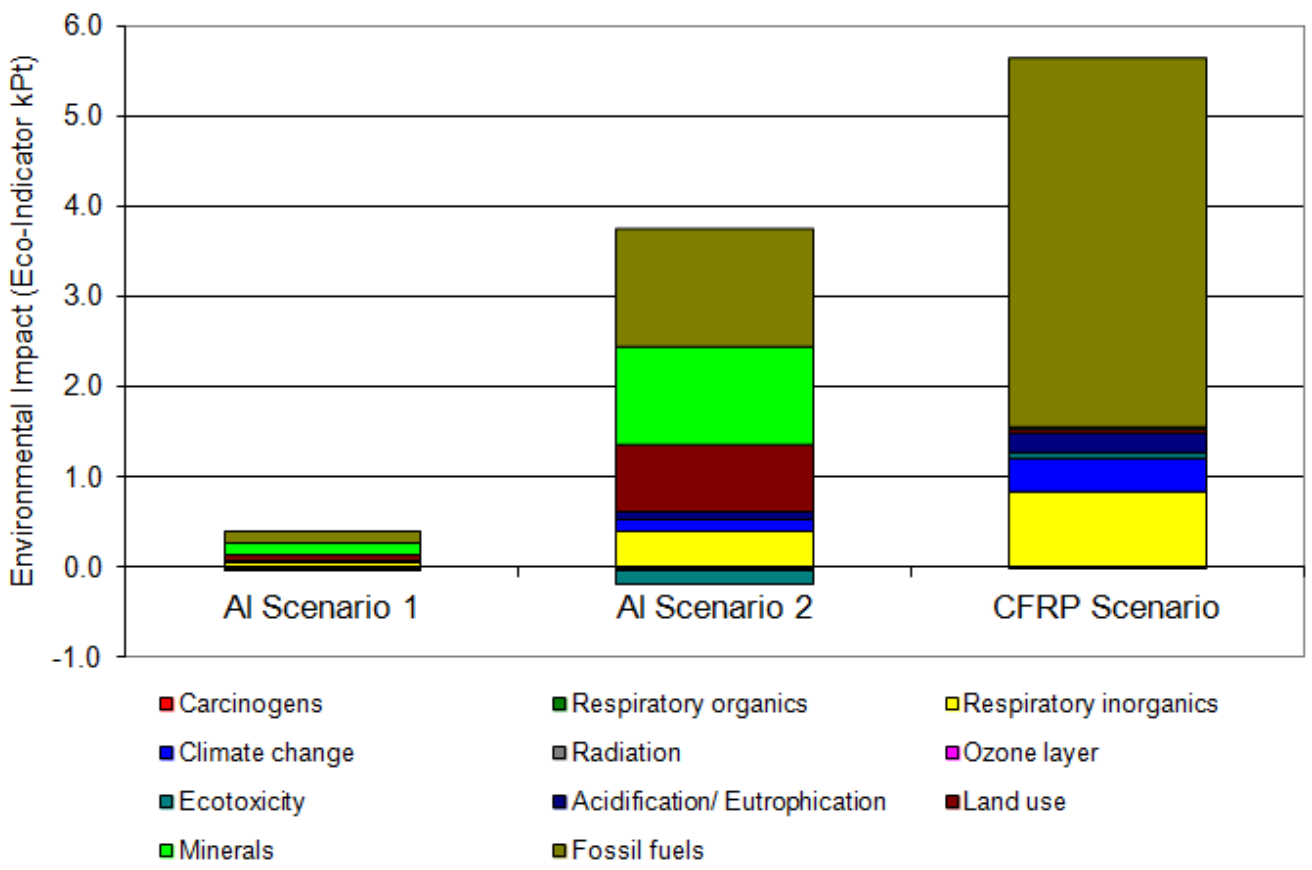

564

$\square$ Minerals

口Fossil fuels

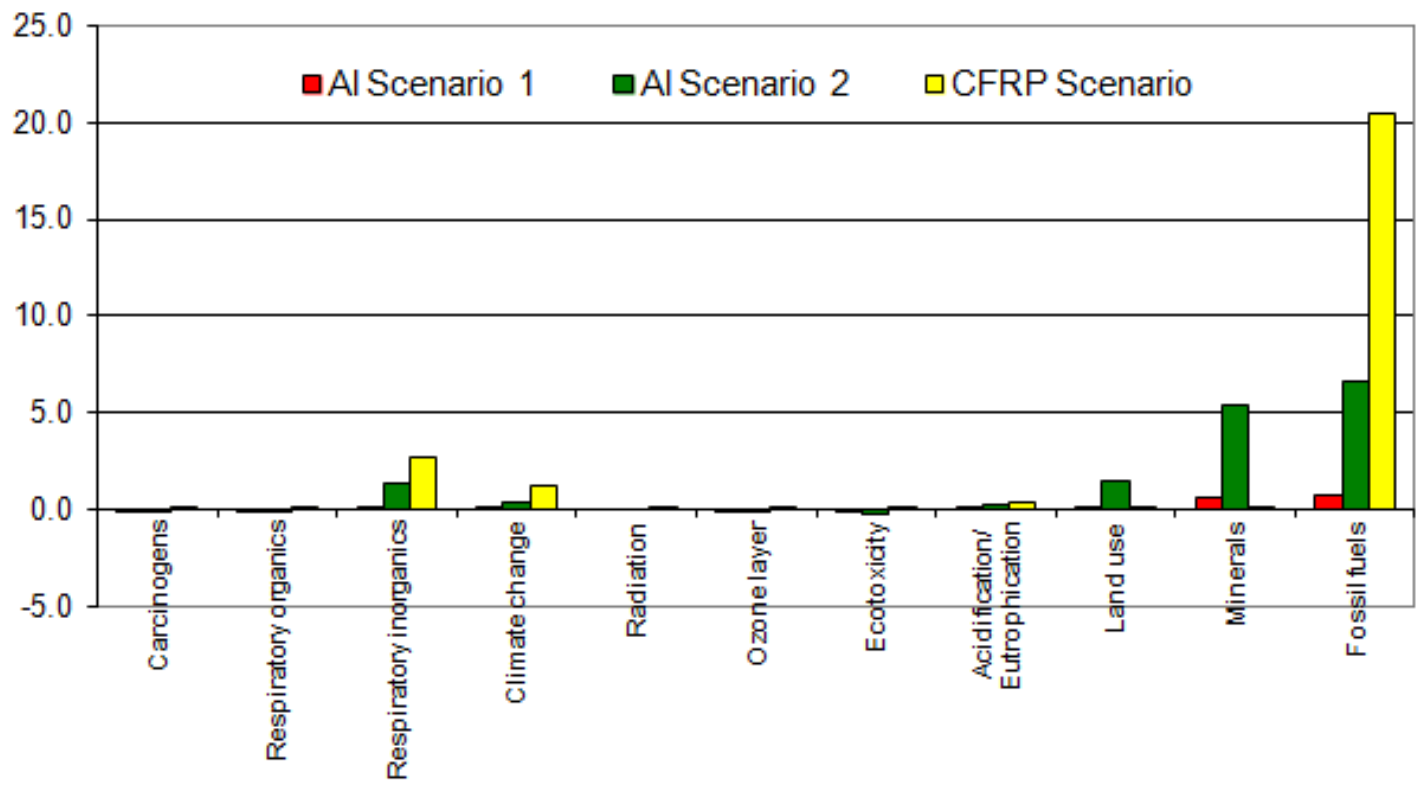



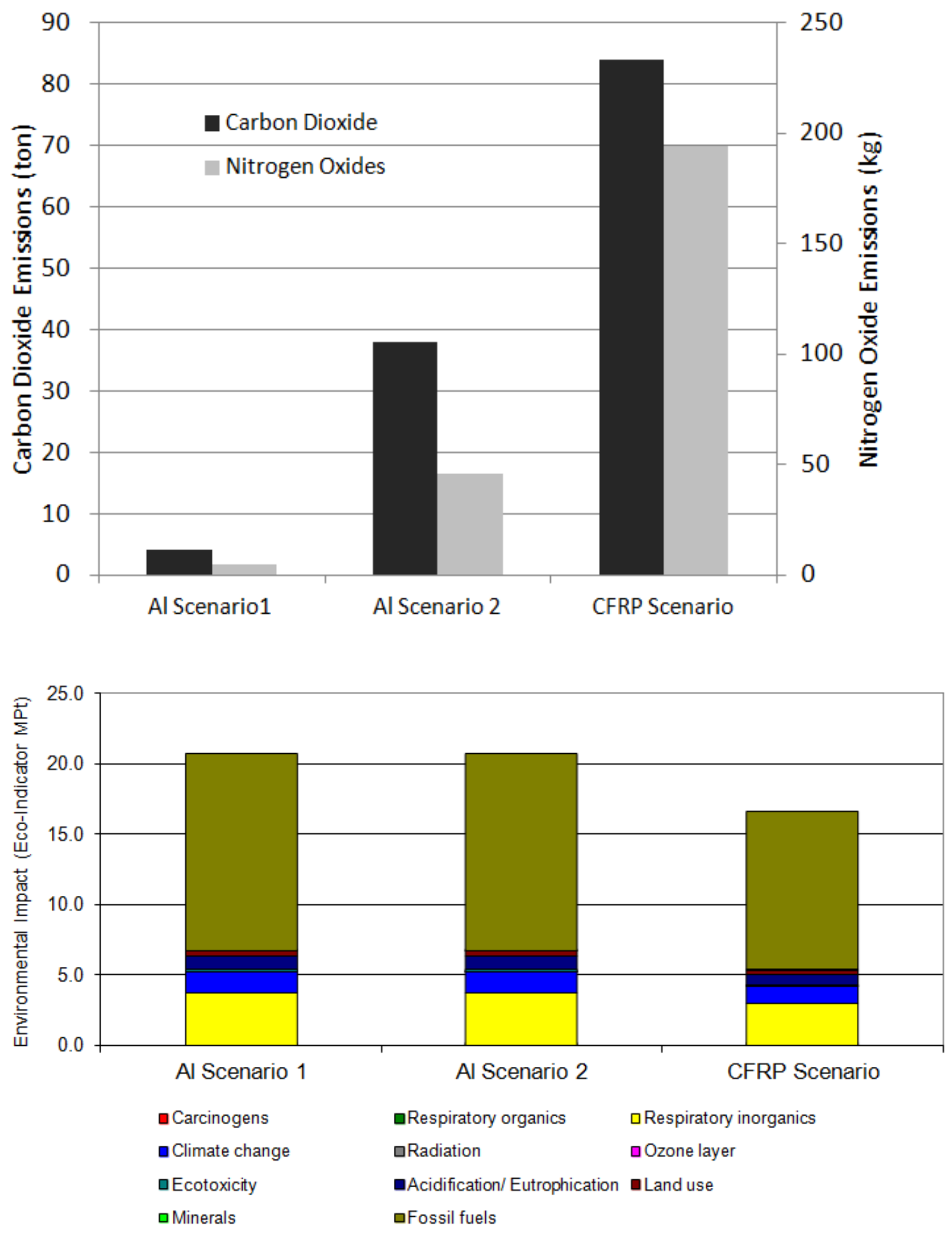


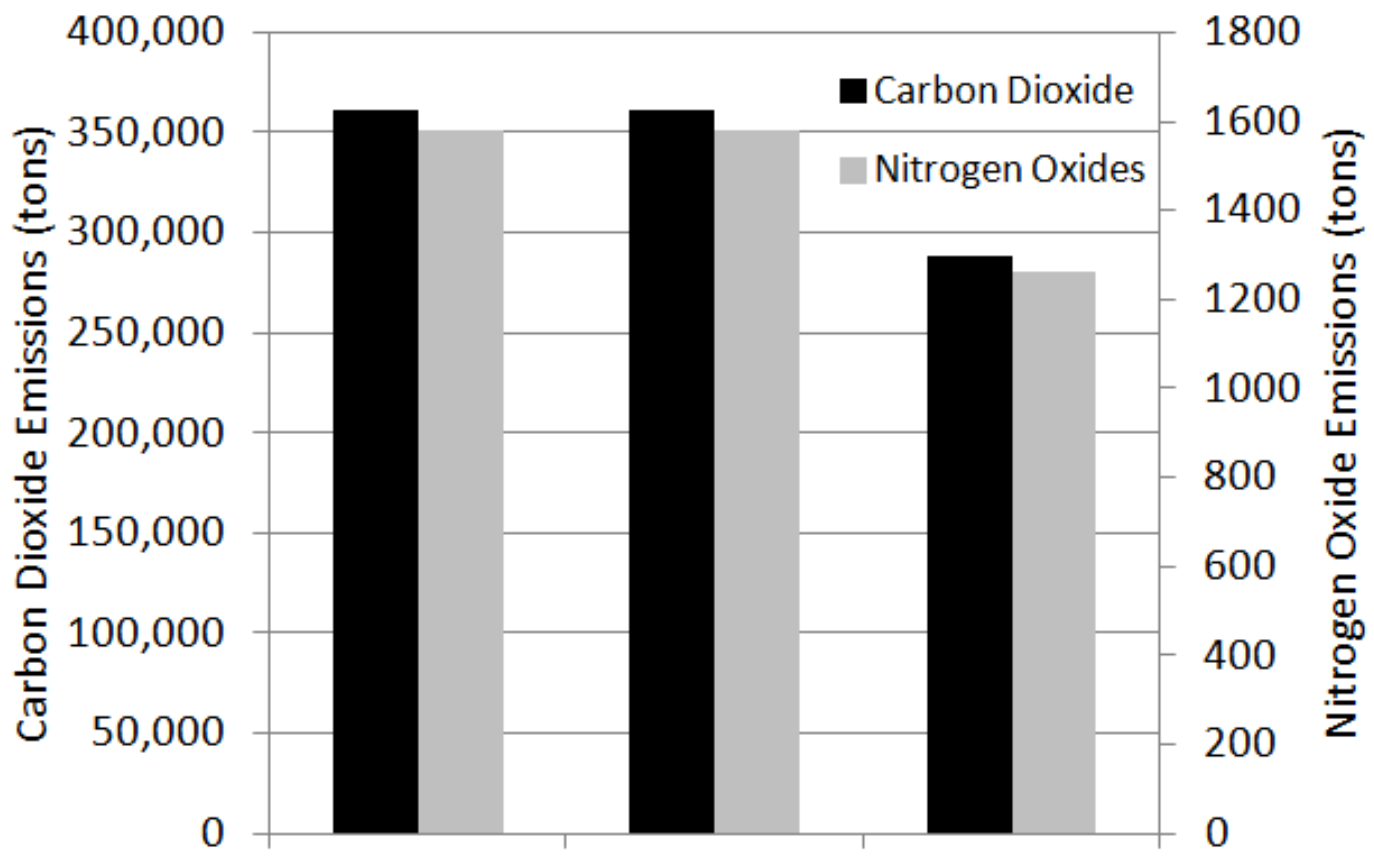

Al Scenario 1 Al Scenario 2 CFRP Scenario
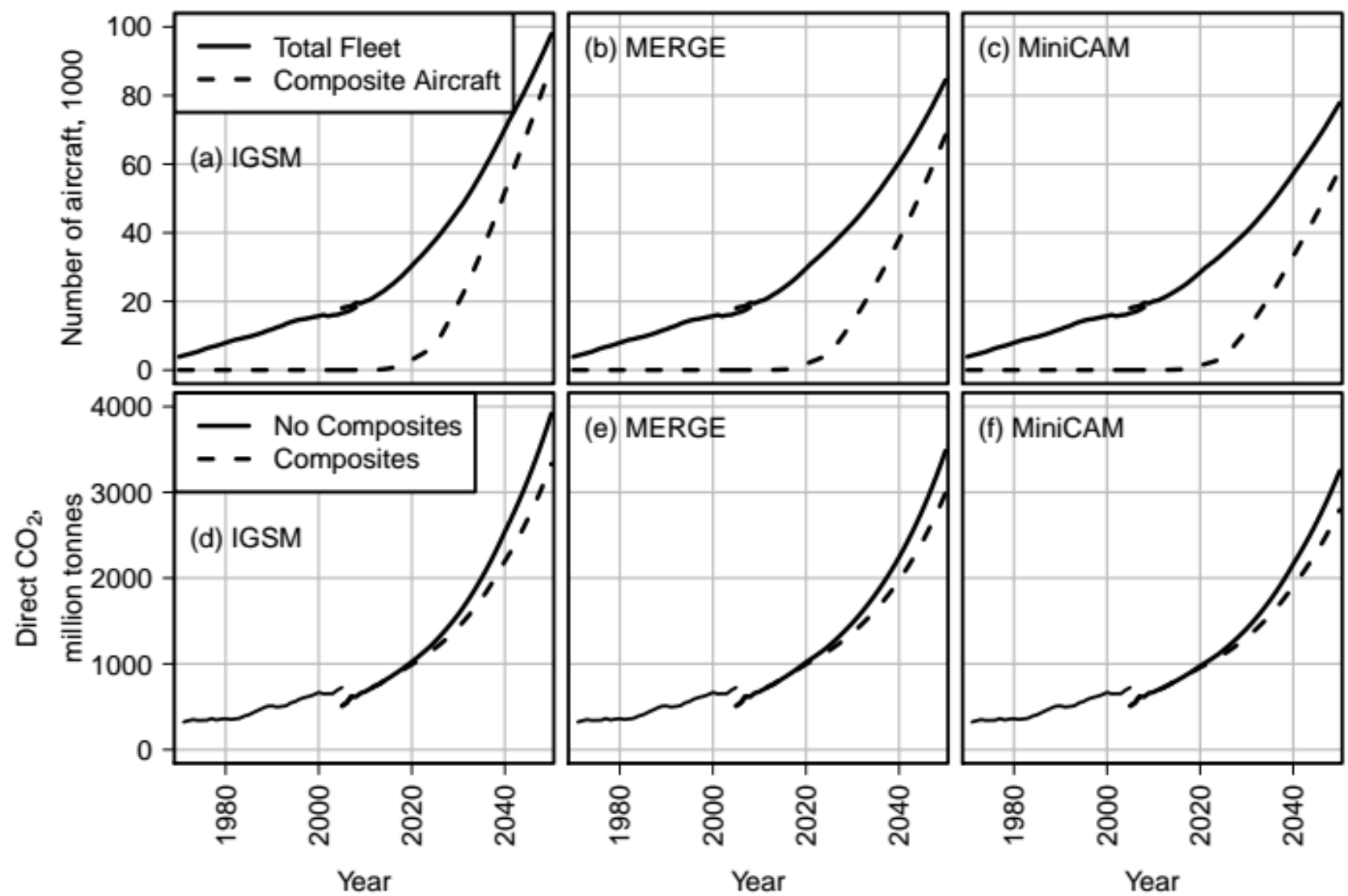

569

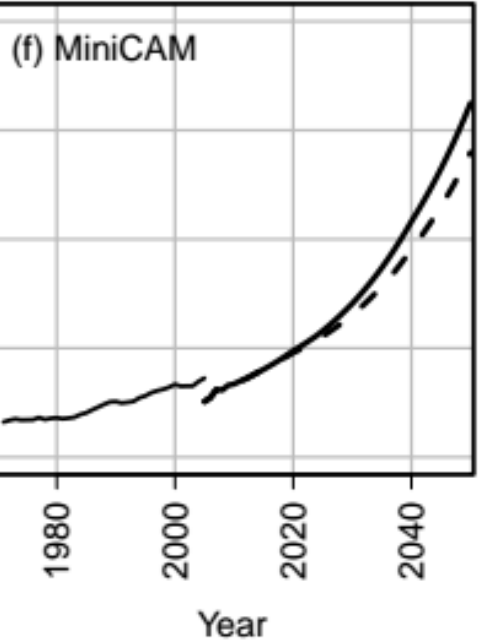

